\title{
Application of Reading Method in the Teaching of College English Writing
}

\author{
Zhipeng Liu \\ School of foreign languages \\ Taishan University \\ Taian, Shandong
}

\begin{abstract}
At present, the English writing scores of college student are unsatisfactory, and the reason of it is that they do few English reading. Reading and writing are mutually reinforcing and interdependent. In practical teaching, teachers shall cultivate students' writing ability in the following aspects: 1) Reading motivation of students shall be motived, and the reading skills shall be cultivated. 2) Reading shall be the studied first to improve the writing ability. 3) The necessary writing skills shall be grasped, and the practical writing ability shall be cultivated.
\end{abstract}

Keywords-reading method; the teaching of college English writing; application

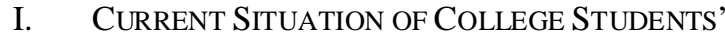 ENGLISH WRITING}

According to the current college English teaching syllabus, undergraduate students shall have elementary writing ability after learning CET-4 course [3]. Therefore, the purpose of writing part in college English test is examining the candidates' writing ability in English. Because the composition can best represent the comprehensive English level of students, it becomes the main part in teaching activities and examinations (usual texts, CET-4 and CET-6). According to the results of the CET- 4 and CET- 6 over the past 10 years, quite a few candidates have failed to meet the requirements of preliminary writing ability, and few people get high scores. And the followings are two reasons. The first aspect is the content. Many candidates are not serious about analyzing question. After viewing the question once or twice, they start writing. The results of it are that the essay is digressed and the key point or the gist they grasp is not deep or very narrow and cannot be extended. Besides, the logical thinking may be disorder, the structure may be disorganized and the subject content may be unfamiliar. The second aspect

Supported by 2017 Shandong Provincial Higher Education Research and Development Program (Humanities and Social Sciences) - "Research on the Constructive Function of Causal Relationship in Academic English Writing" (No. J17RA062); Shandong Social Science Planning Research Project "College English Curriculum Design and College Students Self-study Research on the Correlation of Efficacy (12CWJJ01); 2015 Teaching Reform Research Project of Taishan University - "Practical Research of English Vocabulary Learning for College Students of Sports and Arts Majors Based on Learning Strategy Instruction” (Grant Number 201520); The 10th Batch Teaching Reform Research Project of Taishan University - "The college English teachers' discourse studies in the process of class observation and assessing based on critical discourse analysis theory” (Grant Number 201723) is language. The most prominent problem is that the words are inappropriate and the sentences are not correct. In writing English, many candidates get accustomed to use Chinese expressions. For example, they always translate “他们认为自 己是幸福的(They think they are happy)” into “They think themselves are happy”. Only English words and Chinese characters are paired, and the result is only Chinese meaning, not English syntax.

\section{RELATIONSHIP OF READING AND WRITING}

\section{A. Reading and Writing Are Mutually Reinforcing and Interdependent}

Reading is an important thinking activity of human beings. It uses visual reading of the information recorded in the text, enabling people to communicate extensively without being restricted by time and space. Actually, reading is a complex bilateral communication, which is a meaningful interactive process of people and book. In the process of reading, reader interacts positively with the author by using schema in the brain, achieving creative understanding. Base on this view, when the relationship between reading and writing is noticed, readers may find reading and writing processes are the same, and sharing the key cognitive mechanisms. In 1994, Severina Angelova Balabanova specifically expounded the relationship between them. Writing actually simulates the process of reading, and the process of writing is simulation of reader's reading process; besides, reading is also the action of simulation writing. The reason of it is, in the process of reading, the reader must conjecture the intention of author, play the role of author and understand the intension of author [2]. In 1987, after combining the researches about the relationships between reading and writing, Stotsky pointed out "Writing activities are very useful for reading comprehension, otherwise, methods of improving writing by reading have also proved effective. Studies and experiments on the relationship between the two have shown that reading experience always seems to be related to writing ability, or have influence on writing ability. It shows that reading and writing are two relatively independent and interdependent processes, and they are mutually promoted and improved together. ”. 


\section{B. From the View of Internal Regulations of Language Development, Reading and Writing Skills Are Closely Linked}

In the process of language learning, a lot of inputs of language are certainly important. However, if the language learning only pays attention to obtain language knowledge and ignore the application, they just grasp plenty of linguistic forms which are unconnected and isolated [4]. When they need to using it, they still feel incapable. The effective approaches of language learning are focusing on language output and reinforcing the output practices. Because language knowledge needs repetition to be consolidated and a great deal of language materials must be strengthened many times to retain it firmly in memory. Both English reading and writing belong to category of learning and application of English written language, besides both English reading and writing abilities belong to verbal thinking skill. They are closely connected. Language learning requires a lot of input. And in the process of reading, learners acquire language knowledge from the exterior to interior which is input. Using Language without language knowledge input is like a tree without roots or water without sources. Krashen proposed natural input method in the 1980s. He thought when students were exposed to a lot of comprehensible input (like listening and reading texts), the application ability would be grasped naturally [1]. Lots of comprehensible input in textual level can overall improve the foreign language ability. It is consistent with our common sense and intuition. As an old saying goes, after you have read more than ten thousand volumes, you will find it easy to write as if God were there helping you. On the other hand, writing is the process of reappearing the learner's knowledge from the exterior to interior, which is output. Through large amounts of purposeful reading, the student learns, grasps the language knowledge, obtains and remembers the required information, then stores it.

\section{Writing Can Effectively Promote the Internalization of Language Knowledge}

When students consciously have an access to a lot of language materials, they will learn writing skills, obtain writing experiences and materials, expand their thinking, widen their horizon of knowledge, enrich their thoughts and emotions, improve the abilities of observation and analysis and learn the skill of using English to think and write. The range of using language of learners is expanded by writing, which is benefit to improve the accuracy of language application and the ability of free expression with English. Through a large number of reading and writing practices, students can repeatedly practice the inputted language knowledge, gradually digest, absorb and deepen it, so as to transform the explicit linguistic knowledge into implicit linguistic knowledge, forming their own language generation system, and promoting the automation of language using.

\section{TEACHING STRATEGIES}

Lots of examinees think writing is difficult. They may get nothing to write or can't express clearly. There are two reasons: first, less reading; second, no writing skills. Since the cause of the problem has been found, we should pay more attention to students' knowledge, ability and skills training from now on.

\section{A. Arouse Students' Reading Motivation, and Develop Students' Reading Ability}

It's important to set an exact target for arousing students' subjective initiative and sense of participation [5]. The research at home and abroad about the reading motivation shows: each reader has a specific purpose and unique reading style or pattern, and they will change with reading process. Arousing students' reading motivation is teacher's work. Before reading, the teacher have to make students think materials which they are reading are useful, and reading the materials can help them get reliable information to solve those difficult problems. Students should be lead to read for an exact target by teachers. This kind of reading with target can draw their attention and interest to relevant information about the target tasks, and it can also raise students` reading interests, arouse their strong desire for knowledge, sharpen their understanding ability of the reading passage and enhance learning efficiency. An efficient reader not only possesses substantial language knowledge (words, phrases, sentence forms, grammar etc.), but also analyzes and understands the content comprehensively. They lay emphasis on information of paragraphs and topic sentences and analyze the whole dissertation, so they can get required information [7]. Besides, an efficient reader has to know different reading forms and comprehensively uses different skills and strategies. In addition, efficient readers could analyze the passage and give it a summary to enhance the reading ability.

\section{B. Learn Writing from Reading}

As we all know, listening and reading are input while speaking and writing are output. Only enough input which is good enough to speak or write well can assure a superior output. As the ancients say: "Be familiar with poetry, even you can't poetize but recite.” Only read thousands of books, one can write fluently.” Both of them expressed one meaning, "Writing is often learned from reading." Therefore, it`s better to improve your writing from reading. More reading can give more materials and choices in the exam. And that makes the passage possess the most representative and the most typical materials possible. In this way, the passage can be insightful, powerful and convincing instead of dull, empty or even out of nothing which can get you a zero. We also need to pay attention to learning new language expressions while obtaining information and expanding our knowledge [8]. We should notice that English writing can't be expressed in Chinese language structures. Chinglish like word-for-word translation can only make one fall into a wrong path.

\section{Master Writing Skills}

The grading principle and standard are from two aspects which are content and language. No matter what types of questions, we just need to master the training skills of content and language. And that makes our passage in a high level.

\section{1) Analyze the subject carefully}


Analysis is the first of first in writing. And its purpose is establishing the thought-content which can`t be ignored [6]. Because it's about the whole passage can be a great one or not. When you're doing subject analysis, you'd better draft an outline the first, design a general profile the second and list what' s going to write according to your plan. So the passage will not deviate from the theme and be more clearly because of the overall arrangement.

\section{2) Select materials elaborately}

Doing a great subject analysis and getting the theme are not equal to the whole passage which needs abundant materials to enrich the outline and expound the main idea of the passage completely. Thus, the next step is to make sure the content materials and focus on the thematic idea to write. It's like the bones need flesh and blood to become life and the trunks need branches and leaves to become more flourishing.

\section{3) Coherent language}

The coherence of thought and word is inextricable [9]. The wholeness of the passage should be considered. We could correctly use the conjunctive words (such as but, first, in conclusion, because, therefore, such as, beside etc.) to link up each paragraph thought or even make the linking of each sentence more coherent.

\section{4) Choose words carefully and make sentence smartly}

When you're writing, you have to use words proficiently and properly. And when you're choosing words, you have to do as possible as followings: First, use proper words, distinguish synonyms carefully, be careful of the different meanings of prepositions in each different phrases or structures; Second, use exact words, do not repeat. Third, use specific words, do not left vague impression. For example, "A smile is the salesman's best asset" is more specific than "Friendliness is the sales man's best asset". Using all kinds of basic sentence patterns and flexible conversion can make the passage more vivid and clear. We can use sentential forms like basic sentence pattern, compound sentence, complex sentences, parallelism, inverted sentence, declarative sentence, interrogative sentence, imperative sentence, exclamation sentence. Control sentence length by using punctuation mark, coordinating conjunctions (and, but, or, for), Subordinator (because, although, if, when).

\section{CONCLUSION}

Only reading skills are not enough, we also have to practice by doing lots of writing. From the sentence to paragraph, step by step, you can write creatively or imitate others. Be conscious of your accumulated knowledge and use skills to write passage. Constant revision is just part of the writing, again and again; you can finally get improved constantly.

\section{REFERENCES}

[1] Krashen. The Input Hypothesis: Issues and Implications [M]. NY: Longman, 1985.

[2] Chen Liping. Analyze Model-teaching in Writing-teaching from the Relationship of Reading and Writing [J]. Foreign Languages and Their Teaching), 2001, (4). (In Chinese).

[3] College English Teaching Outline (revised edition) (For undergraduate of higher education)[M].Shanghai: Shanghai Foreign Language Education Press,1999. (In Chinese).

[4] Liang Wenhua, Zhang Lichang. English Writing-teaching Theory and Practice, Based on Reading [J]. Foreign Languages Research, 2016, (5). (In Chinese).

[5] Qi Guohui. Further on the Relevant of Reading and Writing- How to "Improve Writing from Reading”[J]. Journal of Jixi University, 2013, (11). (In Chinese).

[6] Xiao Lan, Tang Shucheng, The Training of Composition Writing Skills [M]. Chengdu: Chengdu University of Science and Technology Press, 1991. (In Chinese).

[7] Yang Wei, Huang Wei, The Integration of Reading and Writing and Its Teaching Strategies [J]. Modern Primary and Secondary Education, 2015, (4). (In Chinese).

[8] Zhang Xinke, Speech Form Affiliation in Reading-teaching and Writingteaching [J]. Teaching Methods in the Course Materials, 2016, (8). (In Chinese).

[9] Zhao Xueqin. The Affection of Reading in College English teaching [J]. Foreign Language World, 2001, (1). (In Chinese). 